\title{
Global reconstruction of twentieth century lake surface water temperature reveals different warming trends depending on the climatic zone
}

Article

Accepted Version

Piccolroaz, S., Woolway, R. I. ORCID: https://orcid.org/00000003-0498-7968 and Merchant, C. J. (2020) Global reconstruction of twentieth century lake surface water temperature reveals different warming trends depending on the climatic zone. Climatic Change, 160 (3). pp. 427-442. ISSN 0165-0009 doi: https://doi.org/10.1007/s10584-020-02663-z Available at https://centaur.reading.ac.uk/88767/

It is advisable to refer to the publisher's version if you intend to cite from the work. See Guidance on citing.

To link to this article DOI: http://dx.doi.org/10.1007/s10584-020-02663-z

Publisher: Springer

All outputs in CentAUR are protected by Intellectual Property Rights law, including copyright law. Copyright and IPR is retained by the creators or other copyright holders. Terms and conditions for use of this material are defined in the End User Agreement. 


\section{www.reading.ac.uk/centaur}

\section{CentAUR}

Central Archive at the University of Reading

Reading's research outputs online 


\section{Title}

2 Global reconstruction of $20^{\text {th }}$ century lake surface water temperature reveals different

3 warming trends depending on the climatic zone

4

5

6

7

\section{Author information}

Sebastiano Piccolroaz ${ }^{1 * \dagger} \uparrow$, R. Iestyn Woolway ${ }^{2} \uparrow$, Christopher J. Merchant ${ }^{3,4}$

1. Independent Researcher. Current affiliation: Free University of Bolzano, Bolzano, Italy

2. Dundalk Institute of Technology, Dundalk, Ireland

3. Department of Meteorology, University of Reading, Reading, UK

4. National Centre for Earth Observation, University of Reading, Reading, UK

$†$ These authors contributed equally to this work

*Corresponding author; email: sebastiano.piccolroaz@gmail.com

\section{ORCID}

Sebastiano Piccolroaz: 0000-0003-1796-7624

R. Iestyn Woolway: 0000-0003-0498-7968

Christopher J. Merchant: 0000-0003-4687-9850

\section{Abstract}

Lake surface water temperatures (LSWTs) are sensitive to climate change, but previous studies have typically focused on temperatures from only the last few decades. Thus, while there is good appreciation of LSWT warming in recent decades, our understanding of longerterm temperature change is comparatively limited. In this study, we use a mechanistically based open-source model (air2water), driven by air temperature from a state-of-the-art global atmospheric reanalysis (ERA-20C) and calibrated with satellite-derived LSWT observations (ARC-Lake v3), to investigate the long-term change in LSWT worldwide. The predictive ability of the model is tested across 606 lakes, with ninety-one percent of the lakes showing a daily Root Mean Square Error smaller than $1.5^{\circ} \mathrm{C}$. Model performance was better at midlatitudes and decreased toward the equator. The results illustrated highly variable mean annual LSWT trends during the $20^{\text {th }}$ century and across climatic regions. Substantial warming is evident after $\sim 1980$ and the most responsive lakes to climate change are located in the temperate regions.

\section{Acknowledgements}

RIW received funding from the European Union's Horizon 2020 Programme for Research and Innovation (Grant Agreement no 640171), and from the European Union's Horizon 2020 research and innovation programme under the Marie Skłodowska-Curie grant agreement No. 791812. The authors acknowledge the European Space Agency funding of the ARC-Lake project. Satellite lake temperature data are available at http://www.laketemp.net. The lake model used is available to download from https://github.com/spiccolroaz/air2water. 
46 Global climate change is increasingly evident from a wide variety of observations (Hulme 2016; Roe et al. 2017; Rogora et al. 2018). Surface air temperature measurements show a rapid increase in global temperature during the $20^{\text {th }}$ century (IPCC 2013), and climate models project continued warming in the future (Cubasch et al. 2001; Meehl et al. 2007). Numerous studies have also shown widespread increases in lake surface water temperature (LSWT) (Schneider and Hook 2010; O'Reilly et al. 2015; Woolway et al. 2017a; Ptak et al. 2018). Such increases are of great importance to aquatic ecology, as changes in lake temperature influence a myriad of physical and ecological processes, including mixing patterns, phenology, and the structure of biotic communities (Adrian et al. 2009; Kraemer et al. 2015; Piccolroaz et al. 2015; Thackeray et al. 2016). Understanding lake thermal responses to climate is therefore critical for predicting biotic change and for anticipating the repercussions of climatic variability on lakes and their associated ecosystems.

While there is sufficient evidence to demonstrate that lakes have warmed in recent decades, our understanding of longer-term temperature change (e.g., extending back before the second half of the $20^{\text {th }}$ Century) is comparatively limited. Global LSWT studies have relied heavily on thermal infrared imagery from spaceborne satellites and, as such, are restricted to the period since the early 1980's (Schneider and Hook 2010; O'Reilly et al. 2015). Other observational methods include paleolimnological temperature proxies (Tierney et al. 2010; Lehnherr et al. 2018) and in-situ measurements (Verburg et al. 2003; Austin and Colman 2008; Kainz et al. 2017; Woolway et al. 2017a; Matulla et al. 2018). However, the lakes investigated using these methods are relatively few in number. The lack of a global $20^{\text {th }}$ century baseline temperature against which recent lake warming can be referenced limits quantitative understanding of LSWT trends observed in recent decades within the context of longer-term variability. For example, several lakes around the world have demonstrated a response to the recent warming 'hiatus' (1998-2012) (Medhaug et al., 2017), and LSWT trends evaluated during the hiatus period may underestimate longer-term warming (Winslow et al. 2018). In addition, analysing the relationship between large-scale teleconnection patterns and fluctuations of LSWT trends found in some regions (Livingstone and Dokulil, 2001; Blenckner et al. 2007; Katz et al., 2011; Salmaso 2012; Ptak et al. 2018) may provide new insights if a long-term global map of LSWT dynamics would be available. The extent to which lake warming has occurred at a global scale during the last century, and how those patterns vary across lakes worldwide, requires further investigation.

Due to the scarcity of in-situ observations, quantifying LSWT change worldwide during the $20^{\text {th }}$ century requires a modelling approach. Trying to make reliable predictions of how LSWT has evolved due to climatic change is difficult. LSWT responds to complex thermodynamic fluxes (Henderson-Sellers 1986; Woolway et al. 2015), hence its precise quantification using process-based numerical models requires detailed over-lake meteorological data (e.g., wind speed, humidity, cloud cover) as inputs (Bruce et al. 2018). In-situ meteorological information of such fine detail is not frequently available above lakes worldwide and over long-time periods and meteorological gridded products are typically associated with coarse spatial resolution and larger uncertainties when extending back prior to the second half of the $20^{\text {th }}$ Century. To overcome this limitation, previous studies have used simple regressive/statistical models (Webb 1974; McCombie 1959; Sharma et al. 2008). 
These require as input only air temperature, a variable that is more often available and commonly more reliable than other meteorological variables (Gleckler et al. 2008). However, regression models are typically not able to address some fundamental physics and their use is controversial when applied with air temperature ranges beyond the limits of the time series used for model calibration (Piccolroaz et al., 2018), as would be expected under climate change.

To overcome the limitations of the aforementioned traditional modelling approaches, Piccolroaz et al. (2013) developed the air2water model, a hybrid model (Toffolon and Piccolroaz 2015) which combines a physically based derivation of the governing lake thermodynamic equations with a statistical calibration of model parameters. The model was developed to retain the simplicity of regression models, such as the limited number of required input variables, while preserving the robustness of deterministic models. air 2 water has been shown to provide similar performance, in terms of simulating LSWT, to processbased models (Toffolon et al. 2014; Piccolroaz 2016), and to be an effective tool to investigate LSWT responses to historic and future climate change (Piccolroaz et al. 2015; Piccolroaz et al. 2016; Wood et al. 2016; Czernecki and Ptak 2018; Piccolroaz et al. 2018; Piccolroaz and Toffolon 2018) also when applied to lakes with different morphological characteristics from around the world (Toffolon et al. 2014; Prats and Danis 2019).

Producing reliable projections of LSWT using only air temperature globally would be a major advantage for many scientific purposes and practical applications. For this reason, in this contribution we use air 2 water forced by a state-of-the-art global air temperature reanalysis product (ERA-20C) to simulate long-term LSWT change in 606 lakes worldwide during the $20^{\text {th }}$ century. Besides showing the potential of this model for global-scale climate change impact studies on lakes, we use the reconstructed LSWT time series to investigate how lakes situated across climatic gradients have responded to climate change since 1900 . Also, while previous studies have focussed on LSWT variations during summer (Jul-Sep) (Austin and Colman 2007; Schneider and Hook 2010; O'Reilly et al. 2015) we focus, in this study, on annually-averaged LSWTs, thus gaining a different, and potentially more insightful, perspective of LSWT change. With this study we aim at contributing to research on the lake thermal dynamics and trends through providing the first global reconstruction of LSWT during the $20^{\text {th }}$ century.

\section{Materials and methods}

2. 1. Study sites and characteristics - The lakes investigated in this study $(n=606)$ were selected based on the availability of satellite-derived LSWT observations (see below). The study sites vary in their geographic and morphological characteristics. They range in altitude between $-216 \mathrm{~m}$ above sea level and 4,753 $\mathrm{m}$ above sea level, in latitude between $54.55^{\circ} \mathrm{S}$ and $74.48^{\circ} \mathrm{N}$, in surface area between $49.06 \mathrm{~km}^{2}$ and $81,844 \mathrm{~km}^{2}$, and in mean depth between $0.1 \mathrm{~m}$ and $738.7 \mathrm{~m}$ (Table $\mathrm{S} 1$ ).

2.2. The air 2 water model - To simulate LSWT in each lake, we used the air 2 water model (Piccolroaz et al. 2013), an open-source model that simulates LSWT relying solely on surface air temperature observations as reasonable proxy for the overall external forcing. It is a zero-dimensional heat budget model to the well-mixed surface volume of the lake, 
133 accounting for all the heat flux components at the lake-atmosphere interface (shortwave

134 radiation, longwave radiation, and diffusive terms) mathematically simplified to obtain a 135 simple ordinary differential equation. The added value of air 2 water compared to purely 136 regressive models is the explicit inclusion of the effect of vertical thermal stratification on 137 lake thermal dynamics through a simple, yet effective, empirical relationship. In this respect, 138 the model showed good ability also to simulate the seasonal evolution of the well-mixed layer 139 thickness (Toffolon et al. 2014; Piccolroaz et al. 2015). A detailed description of the model is 140 available in Text S1 in the Supplementary material.

141 The six model parameters of air2water (see Text S1) were calibrated by optimizing a 142 metric of model performance via an automatic optimization procedure (Particle Swarm 143 Optimization, Kennedy and Eberhart 1995), using only air temperature as input and observed 144 LSWT as reference. In this way, the model is data-driven (Solomatine et al. 2009), while 145 being physically based, allowing for distilling information about the behaviour of the system 146 into the values of the parameters. The model equation was solved numerically by using the 147 Crank-Nicolson numerical scheme with a daily time step.

2.3. Surface air temperature - We downloaded the air temperatures needed to drive air2water from the European Centre for Medium Range Weather Forecasts' (ECMWF) ERA-20C reanalysis product, which provides air temperature at 2-m height above surface at a daily time step and at a grid resolution of $1^{\circ}$ (European Centre for Medium-Range Weather Forecasts, 2014). Time series data were extracted for the grid point situated closest to the centre of each lake, defined as the location of maximum distance to land, calculated using the distance-to-land dataset of Carrea et al. (2015). When the surface elevation of the ERA-20C grid was not equivalent to the elevation of the lake, surface air temperature was corrected to over-lake values using appropriate lapse rates $(\Gamma) . \Gamma$ is variable within short time periods (Rolland 2003), due to, among other things, synoptic circulations (Pagès and Miró 2010) and changing cloud cover (Minder et al. 2010), and therefore in this study we followed the method of Gao et al. (2012). We evaluated site-specific $\Gamma$ by calculating the difference between temperatures at two pressure levels covering the maximum elevation range of a grid (such as $850 \mathrm{hPa}$ and $925 \mathrm{hPa}$ ) and divided through the differences in the corresponding geopotential heights (i.e., the geopotential $\mathrm{m}^{2} \mathrm{~s}^{-2}$ divided by the gravitational acceleration $9.81 \mathrm{~m} \mathrm{~s}^{-2}$ ).

2.4. Satellite-derived lake surface temperature data - The parameters of the air 2 water model were calibrated against satellite-derived lake surface water temperature data from the

168 ARC-Lake v3 dataset (MacCallum and Merchant 2012), available at

169 http://www.laketemp.net. Daily lake-mean time-series were obtained from the spatiallyresolved satellite data by averaging across the lake area. Lake-mean surface temperatures were used in order to average across the intra-lake heterogeneity of LSWT responses to climate change (Woolway and Merchant 2018; Zhong et al. 2018). We used fifteen years 174 Piccolroaz (2016) and Piccolroaz et al. (2018) to be sufficient to generate accurate predictions 175 of LSWT using air2water, also when the time series is affected by large gaps (as is common 
in satellite-derived lake surface temperature due to the presence of clouds). The entire satellite-data period was used to make the derived model parameters as robust as possible.

\subsection{Statistical methods and analysis - The accuracy of air 2 water in simulating} LSWT was evaluated by calculating the Root Mean Square Error (also used as performance metric for model calibration):

3

$$
R M S E=\sqrt{\frac{\sum_{i=1}^{N}\left(\widehat{T}_{w, i}-T_{w, i}\right)}{N}},
$$

and the Nash Sutcliffe Efficiency Index (Nash and Sutcliffe 1970):

$$
N S E=1-\frac{\sum_{i=1}^{N}\left(\widehat{T}_{w, i}-T_{w, i}\right)}{\sum_{i=1}^{N}\left(\widehat{T}_{w, i}-\bar{T}_{w}\right)},
$$

where $\widehat{T}_{w, i}$ and $T_{w, i}$ are the daily observed and simulated LSWT at time $i, \bar{T}_{w}$ is the mean of observed temperature, and $N$ is the length of the observational record. The NSE is a normalized metric that provides an evaluation of model performance relative to the variability of the observed time series. This metric ranges from $-\infty$ to 1: a value of 1 corresponds to a perfect match between measured and simulated values, and a value of 0 indicates that the model prediction is as accurate as using the mean of the observations. In this study, we define the lakes that are reasonably well modelled by air 2 water as those with a NSE of greater than 0.8 .

The statistical metrics above were compared across climatic zones, as identified by the Köppen climate classification (Köppen and Geiger 1930; Köppen 1990), which provides an efficient way to describe climatic conditions defined by multiple variables and their seasonalities. Here, we used the Köppen climate classification for a long-term average climate (1901-2010), using the same criteria as Kottek et al. (2006) and Chen and Chen (2013). The Köppen classification uses monthly temperature and precipitation data averaged over the 1901-2010 period, on a $0.5^{\circ}$ longitude $\mathrm{x} 0.5^{\circ}$ latitude grid. For a fuller account, refer to Chen and Chen (2013). The Köppen climate classification of each lake is given in Table S1. The main characteristics of the Köppen climate zones are described in Table S2.

The long-term variations of air temperature and LSWT were analysed in terms of annually-averaged temperature anomalies relative to the reference period 1951-1980. For each lake, thermal reactivity to changes in air temperature was quantified as the slope of the regression line (without intercept) between annually-averaged air temperature anomalies ( $\mathrm{x}$ axis) and LSWT anomalies (y-axis) over the 1900 to 2010 period (excluding the reference period 1951-1980).

\section{Results}


216 cycle of LSWT is illustrated in Figure 1. We compared the time series of observed and 217 simulated LSWT for five selected case-study lakes (Lake Malombe, Lake Assad, Lake

218 Garda, Lake Tahoe, Har-Hu Lake), one from each of the major Köppen climate classification zones. The calculated daily RMSE of each case-study lake was below $1{ }^{\circ} \mathrm{C}$, and the NSE was above 0.9. Inspection of these time series suggests that the model is able to capture several aspects of the inter-annual variability in LSWT, such as the timing of warming and cooling, and year-to-year differences in the summer maximum and winter minimum. In addition, air2water is able to simulate the presence and timing of ice cover (where applicable) and the annual range in LSWT (Fig. S1).

To extend the evaluation of the ability of air2water to simulate LSWT worldwide we show, in Figure 2, the calculated daily RMSE and NSE for all lakes, inherently characterized by considerably different annual LSWT cycles (see Fig. S2). The calculated RMSE between modelled and observed daily LSWTs across the study sites varied between $0.41{ }^{\circ} \mathrm{C}$ and 2.32 ${ }^{\circ} \mathrm{C}$, with an average value among all the lakes equal to $1.10^{\circ} \mathrm{C}$. The RMSE values were less than or equal to $1.00{ }^{\circ} \mathrm{C}$ in $38 \%$ of the lakes studied, and less than or equal to $1.50{ }^{\circ} \mathrm{C}$ in $91 \%$ of cases. The computed NSE also varied among lakes, ranging between -0.05 and 0.99 , with an average value among all the lakes of 0.90 . A NSE larger than 0.95 was calculated in $74 \%$ of lakes, while a value larger than 0.90 was calculated in $84 \%$ of lakes. Cases of NSE close to 0 were restricted to equatorial lakes, while it rapidly increased to a value close to 1 towards approximately $15^{\circ}$ latitude (North and South, Figs $2 \mathrm{~b}$ and d). As further commented in the Discussion, such low values of this performance metric were primarily linked with the thermal characteristics inherent to these lakes, which are characterized by small variance of observations (see Fig. S2b), rather than with substantial model deficiencies. This is also suggested by the absence of any strong relationship between latitude and the calculated RMSE, which shows relatively small values throughout the range of considered latitudes (Fig. 2c), except for a slight decrease in model performance at higher latitude, in particular northward of $50^{\circ} \mathrm{N}$.

Although latitude can be assumed as a first proxy for mean climatic conditions, we reinforced this analysis by evaluating the two metrics of model performance among the more representative Köppen climate classification zones (Fig. 3). The RMSE in lakes situated within a 'Tropical' climate was $0.87^{\circ} \mathrm{C}(n=80)$, compared to $1.08^{\circ} \mathrm{C}(n=51)$ in lakes situated within a 'Dry' climate, $1.02{ }^{\circ} \mathrm{C}(n=143)$ in lakes situated within a 'Mild temperate' climate, $1.21^{\circ} \mathrm{C}(n=313)$ in lakes situated within a 'Snow' climate, and $1.05^{\circ} \mathrm{C}(n=19)$ in lakes situated within a 'Polar' climate. The RMSE was comparable among the five climatic zones, although slightly smaller values were obtained for 'Tropical' and 'Polar' regions. Conversely, the comparison of the calculated NSE among the Köppen climate classification zones demonstrate clearly that, relative to this metric, model performance was lower in tropical lakes, compared to any other climate zone. In particular, we calculated an average NSE of: Tropical $=0.55$, Dry $=0.95$, Mild temperate $=0.94$, Snow $=0.96$, Polar $=0.92$. However, some lakes situated within the 'Mild Temperate' $(n=7)$ and 'Dry' $(n=1)$ Köppen climate zones also experienced poor model fit $(\mathrm{NSE}<0.5)$, but these were situated at low

257 latitude. Specifically, these lakes were clustered in Central-Eastern Africa (Fig. 2b), 
essentially in a 'Mild Temperate' Köppen climate zone of the type $C f b$, a subtropical oceanic climate that can be found in mountainous locations of some tropical countries (Fig. 3b).

3.2. Global $20^{\text {th }}$ century temperature evolution- Figure $4 \mathrm{a}$ and $\mathrm{b}$ show the modelled LSWT variations (annually-averaged temperature anomalies) of the studied lakes along with the corresponding air temperatures variations, grouped by Köppen climate zones and separated between Northern and Southern Hemisphere, from 1900-2010. The analysis was carried out only on lakes with a NSE higher than $0.8(n=540)$. The results indicate that lake surface temperatures have varied considerably from 1900 to 2010, with substantial differences between lakes in the Northern $(n=479)$ and Southern Hemisphere $(n=61)$ and across Köppen climate zones. For example, while in both Hemispheres a clear warming occurred since the 1980s, different trends emerged during the first half of the century (e.g., prior to 1950). A previous pronounced warming period, during the so called Early Twentieth Century Warming (ETCW) (see e.g., Hegerl et al. 2018), involved all but Tropical lakes in the Northern Hemisphere and particularly lakes in the 'Snow' Köppen climate zone (see also the Discussion for further details). On the contrary, lakes in the Southern Hemisphere were characterized by slower but continuous warming after the 1920s. A synthesis of the warming trends in the two hemispheres and across Köppen climate zones is provided in the Supplementary material (Table S3) for overlapping subperiods of 30 years.

Such distinct LSWT dynamics clearly reflect different air temperature trends, but LSWTs were substantially modulated by the lakes' thermal reactivity, which is different depending on the Köppen climate zones (Fig. 4c; see also Table S3). In all lakes, the thermal reactivity to changes in air temperature quantified through the regression fit described in Section 2.5 was statistically significant $(p<0.01)$. Results are summarized in Figure $4 c$, grouped by climate zones. On average the annually-averaged thermal reactivity, was higher (i.e., more responsive lakes) for the 'Mild Temperate' zone (median value of 0.55), and lower (i.e., more resilient lakes) for the 'Snow' and 'Polar' zones (median value of 0.17 and 0.18 , respectively; see also Fig. S3). Lakes in the 'Tropical' and 'Dry' climate regions had intermediate values (median value of 0.48 and 0.36 , respectively). The effects on LSWT response to air temperature trends are clear. In the Northern Hemisphere, after the 1990s air temperature in the 'Polar' and 'Snow' regions warmed more than in the other climate regions, but LSWT did not respond considerably as an annual average. Conversely, lakes in the 'Mild Temperate' region experienced a significant warming, almost four times more intense than in the 'Polar' and 'Snow' regions (on average $0.48^{\circ} \mathrm{C} v s .0 .12^{\circ} \mathrm{C}$, relative to the reference period 1951-1980; see also Table S3 for an overview of the different air temperature and LSWT warming trends across Köppen climate zones).

The low thermal reactivity observed in lakes that freeze in winter (particularly in the 'Polar' and 'Snow' regions) are, at least partially, ascribable to the insulating effect of the ice-cover, which inhibits heat exchange at the lake-atmosphere interface. As expected, the same slope of the regression line between annually-averaged air temperature anomalies and LSWT anomalies evaluated considering only the ice-free period indicated clearly higher thermal reactivity in all but 'Tropical' lakes (since these lakes do not freeze), and particularly in lakes located in the 'Snow' and 'Polar' regions (Fig. S4). This is coherent with previous studies that suggested that deep and cold lakes exhibit an amplified response of LSWT to 
changes in air temperature in summer (Piccolroaz et al. 2015; Zhong et al. 2016; Woolway and Merchant 2017). Despite this amplification effect expected for deep lakes in the 'Snow', 'Polar' and cold 'Dry' regions, however, on an annual basis the lakes located in the 'Mild Temperate' region are confirmed to be the most thermally responsive.

\section{Discussion}

Many earlier studies have used models to simulate LSWT change, but these have typically focused on individual lakes (Hadley et al. 2014; Piccolroaz et al. 2018), or a large number of lakes within a confined region (Hondzo and Stefan 1993; Read et al. 2014; Winslow et al. 2017a; Woolway et al. 2017a; Czernecki and Ptak 2018; Prats and Danis 2019). In addition, a large proportion of previous studies have used models that require a number of meteorological variables. Prior to this investigation, no known studies have simulated LSWT responses to climate change in lakes worldwide by using surface air temperature as the only climatic driver.

For many of the 606 studied lakes, air2water was able to predict accurately LSWT during the satellite-period. One of the most relevant features of the air2water simulations was that the model was able to reproduce accurately inter-annual fluctuations of LSWT. This is particularly remarkable considering that air temperature from reanalysis at grid resolution of $1^{\circ}$ was used in the model calibration. The air 2 water model performed best, as evaluated by NSE, in non-tropical lakes. In general, a decrease in model performance can be observed towards the equator. However, we must note that this is predominantly a result of the minimal seasonal variability of LSWT in these lakes and is inherent in the definition of NSE. Specifically, lakes at low latitudes (i.e., lower than $15^{\circ}$ North and South) typically experience a seasonal range of $<5{ }^{\circ} \mathrm{C}$ compared to $>25{ }^{\circ} \mathrm{C}$ in some temperate lakes (Fig. S2). Thus, the same RMSE between observed and modelled LSWT has a greater impact on model accuracy, in terms of NSE, in near-equatorial lakes. However, we notice that the worst model performance was bounded between $15^{\circ} \mathrm{S}$ and $15^{\circ} \mathrm{N}$, while in the remainder of the tropical region it was comparable to that of lakes located in the other climatic regions. In this regard, among the 66 lakes excluded from the analysis because associated to NSE values lower than 0.8 , the $92 \%$ was between $15^{\circ} \mathrm{S}$ and $15^{\circ} \mathrm{N}$ and the $83 \%$ belonged to the 'Tropical' region.

Besides the clear predictive value of this simple tool, air 2 water has also some limitations. Surface air temperature is closely related to some of the heat fluxes controlling the net surface energy budget in lakes, such as surface radiation, which is typically a dominant heating term at the lake surface (Schmid and Köster 2016). This allows LSWT to be modelled as a function of air temperature alone in some lakes (Livingstone and Lotter 1998). However, other variables such as humidity and wind speed, can influence greatly the lake surface energy budget and thus LSWT (Edinger et al. 1968). For example, tropical lakes experience higher latent heat loss, compared to lakes situated in other climate zones, as a result of the Clausius-Clapeyron relationship whereby the air-water humidity difference, to which the latent heat flux is proportional, increases with decreasing latitude (Woolway et al. 2018). In addition, abundant precipitation can contribute to the heat budget of these lakes (Rooney et al. 2018), and the atmospheric boundary layer is typically unstable (Woolway et al. 2017b) resulting in enhancement of near-surface wind speed and greater turbulent heat loss. Some of these contributions are, at least partially, accounted for in the seasonal term 
included in the air2water model, although they do not explicitly appear in the model equations (see Text S1 and Fig. S6 in the Supplementary material)

Modelled LSWT also demonstrate a slight decrease of model performance towards higher latitude, in particular in lakes situated in northern Siberia and northern North America. This could indeed be an artefact in the LSWT data used in the model calibration, such that these lakes are typically ice-covered for a large part of the year, thus reducing the number of observational points available for calibration. Additionally, a physically-based ice module has not yet been implemented in the air 2 water model, possibly affecting its performance when applied to lakes that freeze in winter, although the current version of the model has showed good performance also in these cases (Toffolon et al. 2014; Piccolroaz et al. 2015; Czernecki and Ptak 2018; Piccolroaz and Toffolon 2018). Finally, we should notice that also hydrological (e.g., groundwater and snow-melting inflows) and anthropogenic (e.g., sewage inflows, cooling/heating systems) factors may affect model performance in some lakes, which are only implicitly included in the formulation of the model.

Given the relatively short duration of the satellite-period, independent model validation was renounced in favour of a more robust calibration of parameters (model validity has been widely demonstrated in several previous applications). This allowed us to reconstruct the global $20^{\text {th }}$ century LSWT evolution with a certain degree of confidence for the first time, contributing to improved understanding of recent and past evolution of lake thermal dynamics worldwide. The LSWT hindcast period covered also the ETCW pronounced warming period, which mainly involved lakes in the Northern Hemisphere (Fig. 4a). The ETCW period has been attributed to a combination of external forcing and internal decadal variability, and it is visible also in other global temperature datasets such as HadCRUT4 (see e.g., Hegerl et al. 2018). It was particularly prominent over high latitudes of the Northern Hemisphere, and encompassed exceptional events as for example the Greenland warming in the 1920s-1930s (Chylek et al. 2006) and the 'Dust Bowl' drought and heat waves in North America in the 1930s (Cowan et al. 2017). The effects on LSWT are appreciable from some of the few long-term time series covering this period (Magee and $\mathrm{Wu}$, 2017; Potemkina et al. 2017), although due to data scarcity they received little attention. The results presented here provide first evidence and quantification of a systematic warming of high latitude lakes in the Northern Hemisphere during the ETCW, which for lakes in the 'Snow' climate region was more than twice the recent warming (anomalies relative to the reference period $1951-1980$ of $0.31^{\circ} \mathrm{C}$ in the $1920-1940$ vs. $0.12^{\circ} \mathrm{C}$ in the $\left.1990-2010\right)$. We stress that the magnitude of such warming is inherently dependent on the accuracy of the reanalysis product used in the analysis, which, despite the well-recognized good reliability of the ERA-20C dataset, may further improve in the future. In this regard, we should notice that the ERA-20C dataset is affected by changes in the observing system, especially in regions of sparse coverage as for example the Southern Hemisphere or during periods such as around World War II due to non-standard observing practice during wartime (Poli et al., 2016).

The present analysis focused on annually-averaged temperatures, offering a change of paradigm compared to the recent tendency towards focusing on long-term changes in summer LSWT (Schneider and Hook 2010; O'Reilly et al. 2015; Sharma et al. 2015). Although summer-averaged LSWT have undoubtedly been pivotal in our understanding and for evaluating the direction of warming globally, they cannot be assumed as representative of the 
overall thermal response of lakes, due to the existence of substantial seasonal variations in LSWT warming rates (Winslow et al. 2017b; Woolway et al. 2017a; Toffolon et al., 2020) primarily modulated by stratification dynamics (Piccolroaz et al. 2015; Zhong et al. 2016). Specifically, lakes thermal reactivity to changes in air temperature is much higher in summer due to strong thermal stratification, thus lower thermal inertia (Piccolroaz et al. 2015). This is exemplified by the larger values of the thermal reactivity illustrated by Schmid et al. (2014) considering equilibrium LSWT (a proxy for summer lake temperature), compared to our results based on annual averages (Figure 4c).

Analysing annual averages in this study allowed us to obtain an integrated overview of lakes thermal dynamics overcoming the seasonal-specific validity of previous global trends. We claim that this is a first step towards extending our understanding of lakes thermal behaviours to all seasons. In fact, not only the intensity but also the timing of air temperature variations crucially affects the extent to which lake surface temperature changes (Piccolroaz et al. 2015; Zhong et al. 2016). In this regard, we note that the lakes thermal sensitivity evaluated in this analysis (Fig. 4c) should be intended as an average value for the study period, while locally it may undergo changes depending on specific air temperature variations throughout the season, possibly modulated also by the insulating effect of the ice cover in lakes that freeze in winter. In addition, morphological factors such as mean depth are known to affect lakes thermal inertia (Toffolon et al. 2014), explaining part of the variability of the computed lakes thermal sensitivity within the same climatic group (Fig. 4c). However, this did not prevent from identifying marked differences across the climatic zones (Fig. S5), with lakes in the 'Mild Temperate' region being the most responsive to air temperature changes, but adds another element to be carefully considered in future analyses.

\section{Conclusions}

In this study we presented the first reconstruction of the global $20^{\text {th }}$ century LSWT evolution and contributed to improved understanding of the impact of climate change on lake thermal dynamics worldwide. To this end, we used a simple, but mechanistically based model, air 2 water, which relies on air temperature as the only climate input. In terms of RMSE between observed and modelled daily temperatures, air2water was able to simulate the surface temperature of many lakes to within $1.5^{\circ} \mathrm{C}$, similar to the performance achieved by other, more computationally expensive models, which require additional meteorological input data (Stefan et al. 1998; Peeters et al. 2002; Thiery et al. 2014; Zhong et al. 2016; Prats and Danis 2019).

The results illustrated highly variable LSWT trends during the $20^{\text {th }}$ century and across climatic regions, with lakes located in the temperate regions being the most thermally responsive. Substantial warming was evident after $\sim 1980$ in both hemispheres, while a previous pronounced warming period was found in the Northern Hemisphere providing first evidence of a systematic warming of high latitude lakes during the so called Early Twentieth Century Warming period (1920-1940).

The modelled annually-averaged LSWT and the corresponding air temperature data are made available in the Supplementary material for all lakes (limited to lakes with NSE $>0.8$; Tables S4 and S5), along with their linear trends calculated separately for the Northern and Southern Hemispheres and for the Köppen climate major groups for 
overlapping subperiods of 30 years (Table S3). The aim is to offer a global $20^{\text {th }}$ century baseline, against which observed and projected lake warming and future applications based on new reanalysis products can be referenced.

\section{References}

Adrian R, O'Reilly CM, Zagarese $\mathrm{H}$ et al (2009) Lakes as sentinels of climate change. Limnol Oceanogr 54(6):2283-2297. doi:10.4319/lo.2009.54.6_part_2.2283

Austin JA, Colman SM (2008) A century of temperature variability in Lake Superior. Limnol Oceanogr 53(6):2724-2730. doi:10.4319/lo.2008.53.6.2724

Blenckner T, Adrian R, Livingstone DM et al (2007) Large-scale climatic signatures in lakes across Europe: a meta-analysis. Glob. Change Biol., 13:1314-1326. doi: 10.1111/j.1365-2486.2007.01364.x

Bruce L, Frassl M, Arhonditsis GB et al (2018) A multi-lake comparative analysis of the General Lake Model (GLM): Stress-testing across a global observatory network. Environ Modell Softw 102:274-291. doi:10.1016/j.envsoft.2017.11.016

Carrea L, Embury O, Merchant CJ (2015) Datasets related to in-land water for limnology and remote sensing applications: Distance-to-land, distance-to-water, water-body identifier and lake-centre co-ordinates. Geosci Data J 2(2):83-97. doi:10.1002/gdj3.32

Chen D, Chen HW (2013) Using the Köppen classification to quantify climate variation and change: An example for 1901-2010. Environmental Development 6:69-79. doi: 10.1016/j.envdev.2013.03.007

Chylek P, Dubey MK, Lesins G (2006) Greenland warming of 1920-1930 and 19952005. Geophys Res Lett 33:L11707. doi:10.1029/2006GL026510.

Cowan T, Hegerl GC, Colfescu I et al (2017) Factors contributing to record-breaking heat waves over the great plains during the 1930s Dust Bowl. J Clim 30:2437-2461. doi:10.1175/JCLI-D-16-0436.1

Cubasch U, Mehl GA, Boer GJ et al (2001) Projections of future climate change, Climate Change 2001: The Scientific Basis, J. T. Houghton et al., Eds., Cambridge University Press, 525-582

Czernecki B, Ptak M (2018) The impact of global warming on lake surface water temperature in Poland - the application of empirical-statistical downscaling, 1971-2100. J Limnol 77(2):330-348. doi:10.4081/jlimnol.2018.1707

Edinger JE, Duttweiler DW, Geyer JC (1968) Response of water temperatures to meteorological conditions. Water Resour Res 4:1137-1143. doi: 10.1029/WR004i005p01137

European Centre for Medium-Range Weather Forecasts (2014), ERA-20C Project (ECMWF Atmospheric Reanalysis of the 20th Century). Research Data Archive at the National Center for Atmospheric Research, Computational and Information Systems Laboratory, Boulder, Colo. (Updated daily.) Accessed 04 Apr 2018, doi: 10.5065/D6VQ30QG

Gao L, Bernhardt M, Schulz K (2012) Elevation correction of ERA-interim temperature data in complex terrain. Hydrol Earth Syst Sci 16:4661-4673. doi:10.5194/hess-16-46612012 
Gleckler PJ, Taylor KE, Doutriaux C (2008) Performance metrics for climate models. J Geophys Res 113:D06104. doi:10.1029/2007JD008972

Hadley KR, Paterson AM, Stainsby EA et al (2014) Climate warming alters thermal stability but not stratification phenology is a small north-temperate lake. Hydrological Processes 28:6309-6319. doi:10.1002/hyp.10120

Hegerl CH, Brönnimann S, Schurer A, Cowan T (2018) The early 20th century warming: Anomalies, causes, and consequences. WIREs Clim Change 9:e522. doi:10.1002/wcc.522

Henderson-Sellers B (1986) Calculating the surface energy balance for lake and reservoir modelling: a review. Rev Geophys 24:625-649. doi:10.1029/RG024i003p00625

Hondzo M, Stefan HG (1993) Regional water temperature characteristics of lakes subjected to climate change. Clim Change 24(3):187-211. doi:10.1007/BF010918293

Hulme PE (2016) Climate change and biological invasions: evidence, expectations, and response options. Biological Reviews 92:1297-1313.doi: 10.1111/brv.12282

IPCC (2013) Climate Change 2013: The Physical Science Basis. Contribution of Working Group I to the Fifth Assessment Report of the Intergovernmental Panel on Climate Change. In: Cambridge University Press. (ed Stocker TF, D. qin, G. -K. Plattner, M. Tignor, S. K. Allen, J. Boschung, A. Nauels, Y. Xia, V. Bex, and P. M. Midgley), Cambridge, United Kingdom and New York, NY, USA

Katz SL, Hampton SE, Izmest'eva LR and Moore MV (2011) Influence of long-distance climate teleconnection on seasonality of water temperature in the world's largest lake - Lake Baikal, Siberia. PLoS ONE 6(2):e14688. doi:10.1371/journal.pone.0014688

Kainz MJ, Ptacnik R, Rasconi S, Hager HH (2017) Irregular changes in lake surface water temperature and ice cover in subalpine Lake Lunz, Austria. Inland Waters 7:27-33. doi:10.1080/20442041.2017.1294332

Kennedy J, Eberhart RC (1995) Particle swarm optimization, p. 1942-1948. In Proceedings of IEEE International Conference on Neural Networks, Institute of Electrical \& Electronics Engineering, University of Western Australia, Perth, Western Australia

Köppen W (1990) Versuch einer Klassifikation der Klimate, vorzugsweise nach ihren Beziehungen zur Pflanzenwelt. Geographische Zeitschrift 6:657-679

Köppen W, Geiger R (1930) Handbuchder Klimatologie, Gebrueder Borntraeger, Berlin Kottek M, Grieser J, Beck C et al (2006) World Map of the Köppen-Geiger climate classification updated. Meteorol Z 15:259-263. doi:10.1127/0941-2948/2006/0130

Kraemer BM, Hook S, Huttula T et al (2015) Century-long warming trends in the upper water column of Lake Tanganyika. PLoS ONE 10(7):e0132490. doi:10.1371/journal/pone.0132490

Lehnherr I, St. Louis VL, Sharp M et al (2018) The world's largest High Arctic lake responds rapidly to climate warming. Nat Commun 9:1290. doi:10.1038/s41467-018-03685-Z

Livingstone DM, Lotter AF (1998) The relationship between air and water temperatures in lakes of the Swiss Plateau: a case study with palaeolimnological implications. Journal of Paleolimnology 19:181-198. doi:10.1023/A:1007904817619

Livingstone DM, Dokulil, M (2001). Eighty years of spatially coherent Austrian lake surface temperatures and their relationship to regional air temperature and the North Atlantic Oscillation. Limnol Oceanogr 46:1220-1227. doi:10.4319/1o.2001.46.5.1220 
MacCallum SN, Merchant CJ (2012) Surface water temperature observations of large lakes by optimal estimation. Can J Remote Sens 38:25-44. doi:10.5589/m12-010

Magee MR, Wu CH (2017) Response of water temperature and stratification to changing climate in three lakes with different morphometry. Hydrol Earth Syst Sci 21:62536274. doi:10.5194/hess-21-6253-2017

Matulla C, Tordai J, Schlögl M et al (2018) Establishment of a long-term lake-surface temperature dataset within the European Alps extending back to 1880. Clim Dyn 52:5673-5689. doi:10.1007/s00382-018-4479-6

McCombie AM (1959) Some relations between air temperatures and the surface water temperatures of lakes. Limnol Oceanogr 4:252-258. doi:10.4319/1o.1959.4.3.0252

Medhaug I, Stolpe MB, Fischer EM and Knutti R (2017) Reconciling controversies about the global warming hiatus. Nature 545:41-47. doi:10.1038/nature22315

Meehl GA, Stocker TF, Collins WD et al (2007) Global Climate Projections. In: Climate Change 2007: The Physical Science Basis. Contribution of Working Group I to the Fourth Assessment Report of the Intergovernmental Panel on Climate Change [Solomon, S., D. Qin, M. Manning, Z. Chen, M. Marquis, K.B. Averyt, M. Tignor and H.L. Miller (eds.)]. Cambridge University Press, Cambridge, United Kingdom and New York, NY, USA.

Minder JR, Mote PW, Lundquist JD (2010) Surface temperature lapse rates over complex terrain: lessons from the Cascade Mountains. J Geophys Res Atmos 115:D14122. doi:10.1029/2009jd013493

Nash JE, Sutcliffe JV (1970) River flow forecasting through conceptual models part I - a discussion of principles. J Hydrol 10:282-290. doi:10.1016/0022-1694(70)90255-6

O'Reilly C, Sharma S, Gray DK et al (2015) Rapid and highly variable warming of lake surface waters around the globe. Geophys Res Lett 42:10773-10781. doi:10.1002/2015GL066235

Pagès M, Miró JR (2010) Determining temperature lapse rates over mountain slopes using vertically weighted regression: a case study from the Pyrenees. Meteorol Appl 17:5363. doi:10.1002/met. 160

Peeters F, Livingstone DM, Goudsmit G-H et al (2002) Modeling 50 years of historical temperature profiles in a large central European lake. Limnol Oceanogr 47:186-197. doi:10.4319/lo.2002.47.1.0186

Piccolroaz S (2016) Prediction of lake surface temperature using the air2water model: guidelines, challenges, and future perspectives. Advances in Oceanography and Limnology 7(1):36-50. doi:10.4081/aiol.2016.5791

Piccolroaz S, Calamita E, Majone B et al (2016) Prediction of river water temperature: a comparison between a new family of hybrid models and statistical approaches. Hydrol Process 30(21):3901-3917. doi:10.1002/hyp.10913

Piccolroaz S, Toffolon M, Majone B (2013) A simple lumped model to convert air temperature into surface water temperature in lakes. Hydrol Earth Syst Sci 17:33233338. doi:10.5194/hess-17-3323-2013

Piccolroaz S, Toffolon M, Majone B (2015) The role of stratification on lakes' thermal response: The case of Lake Superior. Water Resour Res 51:7878-7894. doi:10.1002/2014WR016555 
Piccolroaz S, Healey NC, Lenters JD et al (2018) On the predictability of lake surface temperature using air temperature in a changing climate: A case study for Lake Tahoe (U.S.A.). Limnol Oceanogr 63:243-261. doi:10.1002/1no.10626

Piccolroaz S, Toffolon M (2018) The fate of Lake Baikal: how climate change may alter deep ventilation in the largest lake on Earth. Clim Change 150:181-194. doi:10.1007/s10584-018-2275-2

Prats J, Danis PA (2019) An epilimnion and hypolimnion temperature model based on air temperature and lake characteristics. Knowl. Manag. Aquat. Ecosyst 420:8. doi:10.1051/kmae/2019001

Potemkina TG, Potemkin VL, Kotsar OV, Fedotov AP (2018) Climate factors as a possible trigger of modern ecological changes in shallow zone of Lake Baikal (Russia). Int. J. Environ. Stud. 75:86-98. doi:10.1080/00207233.2017.1406727

Poli P, Hersbach H, Dee DP et al (2016) ERA-20C: An Atmospheric Reanalysis of the Twentieth Century. J. Climate, 29:4083-4097. doi:10.1175/JCLI-D-15-0556.1

Ptak M, Sojka M, Choinksi A, Nowak B (2018) Effect of environmental conditions and morphometric parameters on surface water temperature in Polish lakes. Water 10(5):580. doi:10.3390/w10050580

Ptak M, Tomczyk AM, Wrzesiński D (2018) Effect of teleconnection patterns on changes in water temperature in Polish lakes. Atmosphere 9:66. doi:10.3390/atmos9020066

Read JS, Winslow LA, Hansen GJA et al (2014) Simulating 2368 temperate lakes reveals weak coherence in stratification phenology. Ecol Modell 291:142-150. doi:10.1016/j.ecolmodel.2014.07.029

Roe GH, Baker MB, Herla F (2017) Centennial glacier retreat as categorical evidence of regional climate change. Nat Geosci 10:95-99. doi:10.1038/ngeo2863

Rogora M, Buzzi F, Dresti C (2018) Climatic effects on vertical mixing and deep-water oxygen content in the subalpine lakes in Italy. Hydrobiologia 824:33-50. doi:10.1007/s10750-018-3623-y

Rolland C (2003) Spatial and seasonal variations of air temperature lapse rates in alpine regions. J Clim 16:1032-1046, doi:10.1175/15200442(2003)016<1032:SASVOA $>2.0 . \mathrm{CO} ; 2$

Rooney GG. van Lipzig N, Thiery W (2018) Estimating the effect of rainfall on the surface temperature of a tropical lake. Hydrol Earth Syst Sci 22:6357-6369. doi:10.5194/hess22-6357-2018

Salmaso N (2012). Influence of atmospheric modes of variability on a deep lake south of the Alps. Clim. Res.. 51:125-133. doi:10.3354/cr01063

Schmid M, Hunziker S, Wüest A (2014) Lake surface temperatures in a changing climate: a global sensitivity analysis. Clim Chang 124:301-315. doi:10.1007/s10584-014-10872

Schmid M, Köster O (2016) Excess warming of a Central European lake driven by solar brightening. Wat Resour Res 52:8103-8116. doi:10.1002/2016WR018651

Schneider P, Hook SJ (2010) Space observations of inland water bodies show rapid surface warming since 1985. Geophys Res Lett 37:L22405. doi:10.1029/2010GL045059 
608

609

610

611

612

613

614

615

616

617

618

619

620

621

622

623

624

625

626

627

628

629

630

631

632

633

634

635

636

637

638

639

640

641

642

643

644

645

646

647

648

649

650

651

Sharma S, Walker SC, Jackson DA (2008) Empirical modelling of lake water-temperature relationships: a comparison of approaches. Freshw Biol 53:897-911. doi:10.1111/j.1365-2427.2008.01943.x

Solomatine D, See LM, Abrahart RJ (2009) Data-driven modelling: Concepts, approaches and experiments. In: Abrahart R. J., See, L. M., Solomatine, D. P. (eds) Practical Hydroinformatics. Water Science and Technology Library, vol 68. Springer, Berlin, Heidelberg

Stefan HG, Fang X, Hondzo M (1998) Simulating climate change effects on year-round water temperatures in temperate zone lakes. Clim Change 40:547-576. doi:10.1023/A:1005371600527

Thackeray SJ, Henrys PA, Hemming D et al (2016) Phenological sensitivity to climate across taxa and trophic levels. Nature 535:241-245. doi:10.1038/nature18608

Thiery W, Stepanenko VM, Fang X et al (2014) LakeMIP Kivu: evaluating the representation of a large, deep tropical lake by a set of one-dimensional lake models. Tellus A 66:21390. doi:10.3402/tellusa.v66.21390

Tierney JE, Mayes MT, Meyer N et al (2010) Late-twentieth-century warming in Lake Tanganyika unprecedented since AD 500. Nat Geosci 3:422-425. doi:10.1038/NGEO865

Toffolon M, Piccolroaz S (2015) A hybrid model for river water temperature as a function of air temperature and discharge. Environ Res Lett 10:114011. doi:10.1088/17489326/10/11/114011

Toffolon M, Piccolroaz S, Majone B et al (2014) Prediction of surface temperature in lakes with different morphology using air temperature. Limnol Oceanogr 59:2185-2202. doi:10.4319/lo.2014.59.6.2185

Toffolon M, Piccolroaz S, Calamita E (2020) On the use of averaged indices to assess lakes' thermal response to changes in climatic conditions. Environ Res Lett (under review)

Verburg P, Hecky RE, Kling H (2003) Ecological consequences of a century of warming in Lake Tanganyika. Science 301:505-507. doi:10.1126/science.1084846

Webb MS (1974) Surface Temperatures of Lake Erie. Water Resour Res 10:199-210. doi:10.1029/WR010i002p00199

Winslow LA, Hansen GJA, Read JS, Notaro M (2017a) Large-scale modeled contemporary and future water temperature estimates for 10774 Midwestern U. S. Lakes. Sci Data 4, 170053. doi:10.1038/sdata.2017.53

Winslow LA, Read JS, Hansen GJA, Rose KC, Robertson DM (2017b) Seasonality of change: Summer warming rates do not fully represent effects of climate change on lake temperature. Limnol Oceanogr 62:2168-2178. doi:10.1002/lno.10557

Winslow LA, Leach TH, Rose KC (2018) Global lake responses to the recent warming hiatus. Environ Res Lett 13:054005. doi:10.1088/1748-9326/aab9d7

Wood TM, Wherry SA, Piccolroaz S, Girdner SF (2016), Simulation of deep ventilation in Crater Lake, Oregon, 1951-2099. U.S. Geological Survey Scientific Investigations Report 2016-5046, 43 p., http://dx.doi.org/10.3133/sir20165046

Woolway RI, Merchant CJ (2017) Amplified surface temperature response of cold, deep lakes to inter-annual air temperature variability. Sci Rep 7:4130. doi:10.1038/s41598017-04058-0 
652
Woolway RI, Merchant CJ (2018) Intra-lake heterogeneity of thermal responses to climate change: A study of large Northern Hemisphere lakes. J Geophys Res Atmos 123:3087-3098. doi:10.1002/2017JD027661

Woolway RI, Jones ID, Hamilton DP et al (2015) Automated calculation of surface energy fluxes with high-frequency lake buoy data. Env Mod Soft 70:191-198. doi:10.1016/j.envsoft.2015.04.013

Woolway RI, Dokulil MT, Marszelewski W et al (2017a) Warming of Central European lakes and their response to the 1980s climate regime shift. Clim Change 142:505-520. doi:10.1007/s10584-017-1966-4

Woolway RI, Verburg P, Merchant CJ et al (2017b) Latitude and lake size are important predictors of over-lake atmospheric stability. Geophys Res Lett 44:8875-8883. doi:10.1002/2017GL073941

Woolway RI, Verburg P, Lenters JD et al. (2018) Geographic and temporal variations in turbulent heat loss from lakes: A global analysis across 45 lakes. Limnol Oceanogr 63:2436-2449. doi:10.1002/lno.10950

Zhong Y, Notaro M, Vavrus SJ, Foster MJ (2016) Recent accelerated warming of the Laurentian Great Lakes: Physical drivers. Limnol Oceanogr 61:1762-1786. doi:10.1002/lno.10331

Zhong Y, Notaro M, Vavrus SJ (2018) Spatially variable warming of the Laurentian Great Lakes: an interaction of bathymetry and climate. Clim Dynam. 52: 5833-5848. doi:10.1007/s00382-018-4481-z 
Polar: Har-Hu Lake $\left(\right.$ ARC-Lake ID $=302$; lat $=38.31^{\circ}$; lon $=97.59^{\circ}$ )
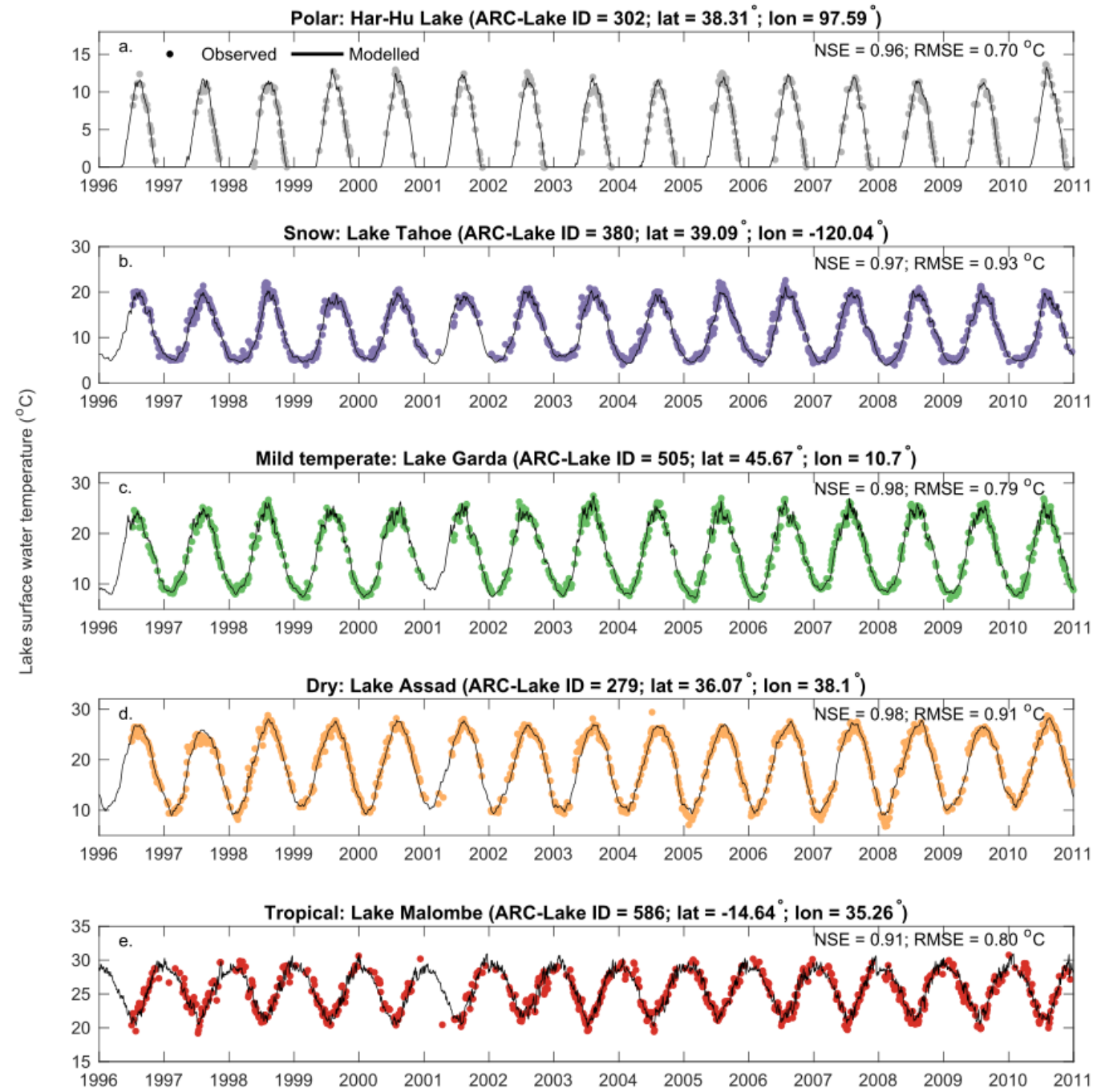

679 Figure 1. Comparison of modelled (solid line) lake surface water temperatures with satellite680 derived (points) temperature observations for (a) Har-Hu Lake (China), (b) Lake Tahoe

681 (United States), (c) Lake Garda (Italy), (d) Lake Assad (Syria), (e) Lake Malombe (Malawi). 682 Shown are the calculated NSE and RMSE between the observed and simulated daily LSWT. 

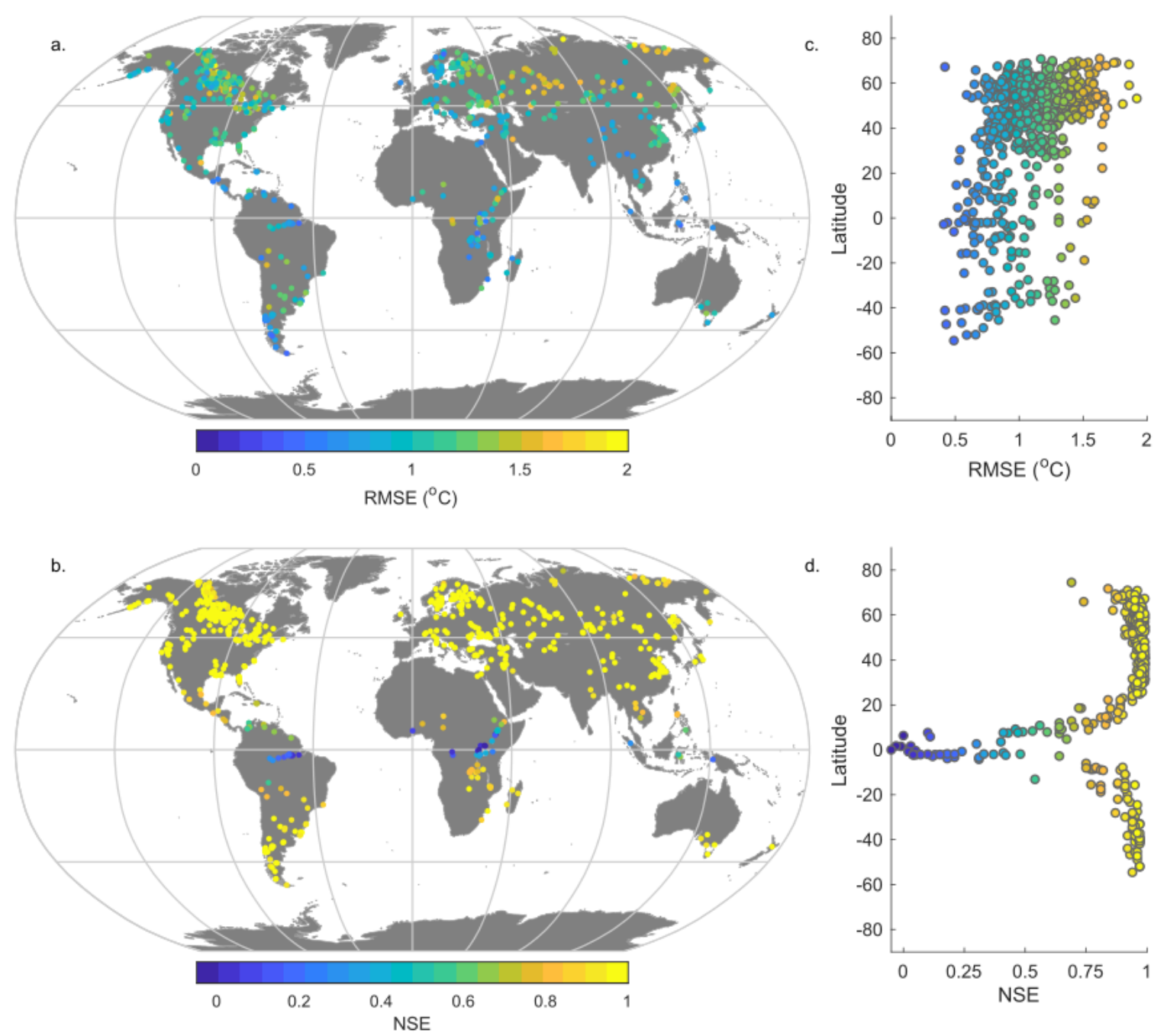

683

684 Figure 2. Global patterns in the computed performance of air2water, evaluated via (a) 685 RMSE and (b) NSE between the observed and simulated daily LSWT. The relationship 686 between latitude and (c) RMSE and (d) NSE are also shown. 
a.
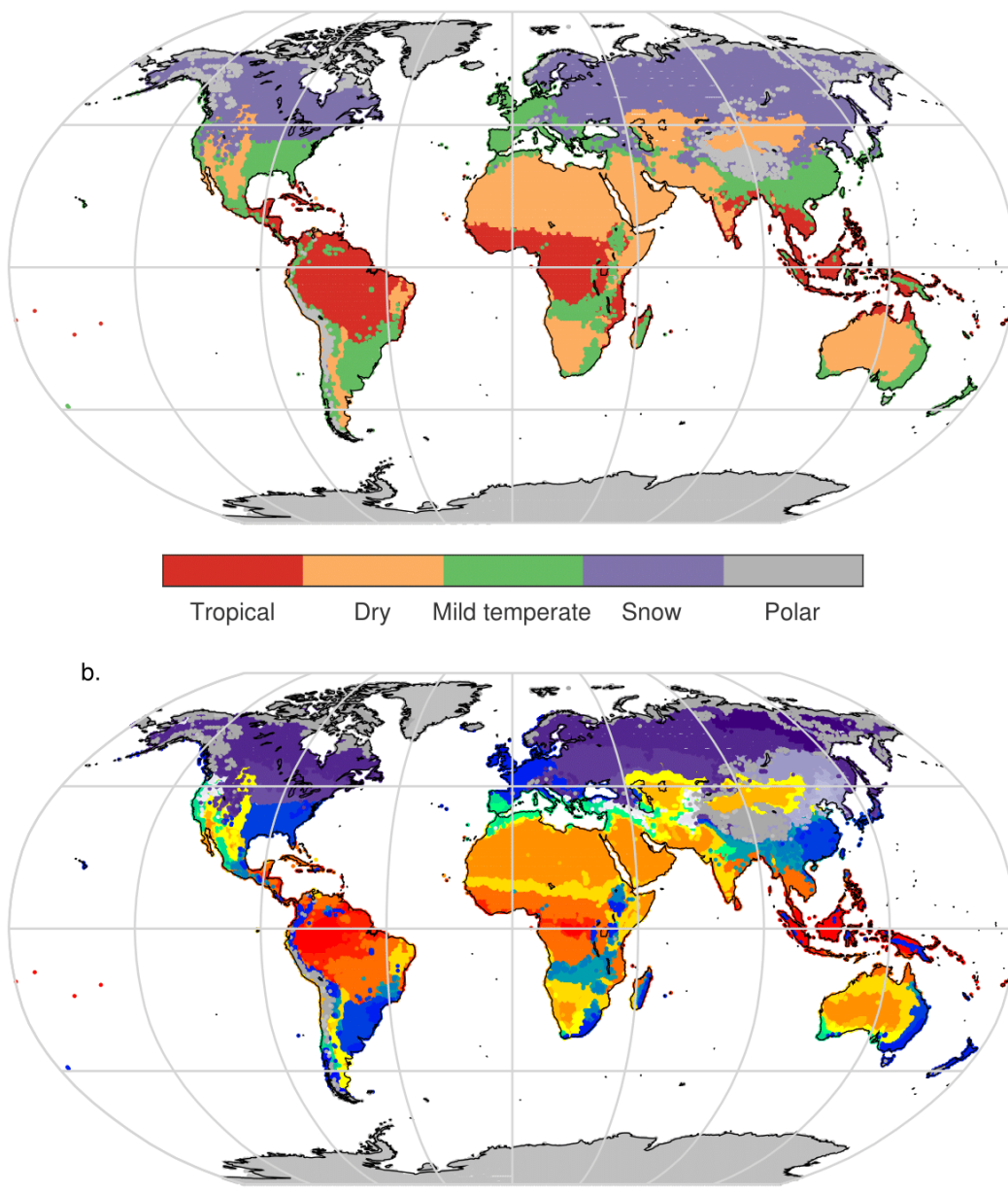

687

688 Figure 3. Relationship between the performance of air2water and the Köppen climate

689 classification, showing both (a) the major climate types and (b) the climate sub-types. Model

690 performance is evaluated by (c) RMSE and (d) NSE between the observed and simulated 691 daily LSWT. c.

d.

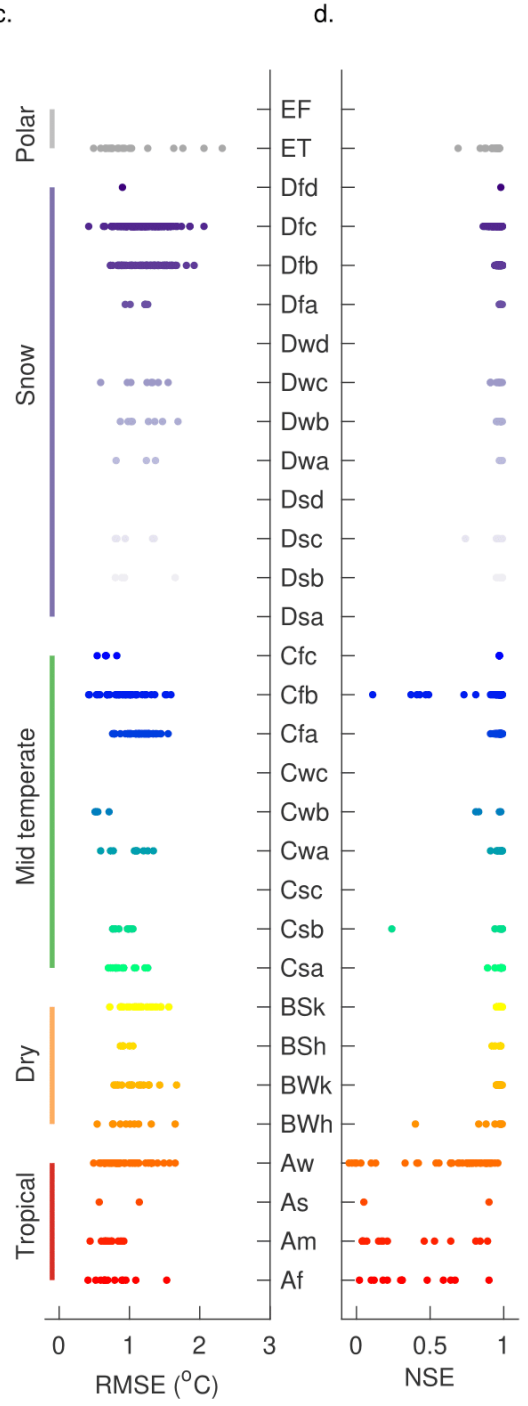

Am BSh Cwa Cfc Dwa Dfb

Aw $\quad$ Csa $=$ Cwc $\square$ Dsb $\quad$ Dwc - Dfd
As $\square$ BSk Cwb Dsa Dwb D D D D D 

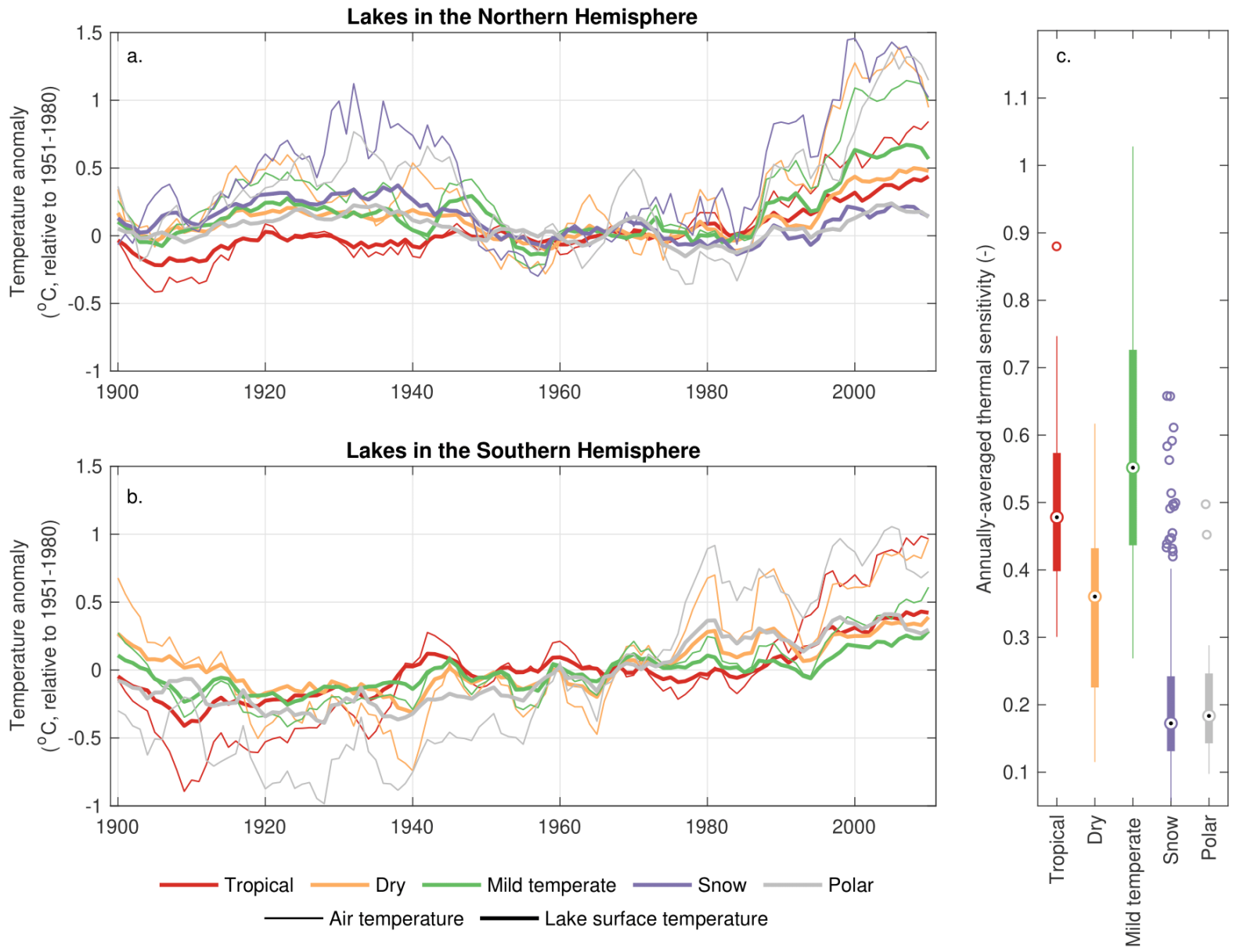

692

693 Figure 4. Long-term LSWT variations for each major Köppen climate zone for the period 694 1900-2010 shown for (a) lakes in the Northern Hemisphere and (b) lakes in the Southern 695 Hemisphere. Only lakes with a NSE higher than 0.8 were included in this long-term analysis.

696 A five-year moving average is applied to the lake and air temperature data. Also shown is 697 lakes thermal sensitivity, defined as the slopes of the regression line between annually698 averaged air temperature anomalies and LSWT anomalies over the 1900 to 2010 period, 699 grouped by climatic region (c). 